\title{
Ecobiophysical Aspects on Nanosilver Biogenerated from Citrus reticulata Peels, as Potential Biopesticide for Controlling Pathogens and Wetland Plants in Aquatic Media
}

\author{
Marcela Elisabeta Barbinta-Patrascu, ${ }^{1}$ Nicoleta Badea, ${ }^{2}$ \\ Camelia Ungureanu, ${ }^{2}$ Stefan Marian Iordache, ${ }^{3}$ Marioara Constantin, ${ }^{1}$ \\ Violeta Purcar, ${ }^{4}$ Ileana Rau, ${ }^{2}$ and Cristian Pirvu ${ }^{2}$ \\ ${ }^{1}$ Faculty of Physics, Department of Electricity, Solid-State Physics and Biophysics, University of Bucharest, 405 Atomistilor Street, \\ P.O. Box MG-11, 077125 Bucharest-Magurele, Romania \\ ${ }^{2}$ Faculty of Applied Chemistry and Material Science, University "Politehnica" of Bucharest, 1-7 Polizu Str., 011061 Bucharest, Romania \\ ${ }^{3}$ Faculty of Physics, 3 Nano-SAE Research Centre, University of Bucharest, P.O. Box MG-38, 077125 Bucharest-Magurele, Romania \\ ${ }^{4}$ National Research \& Development Institute for Chemistry and Petrochemistry-ICECHIM, 202 Splaiul Independentei, \\ 6th District, P.O. Box 35-174, 060021 Bucharest, Romania
}

Correspondence should be addressed to Nicoleta Badea; nicoleta.badea@gmail.com and Camelia Ungureanu; ungureanucamelia@gmail.com

Received 2 February 2017; Revised 3 April 2017; Accepted 20 April 2017; Published 29 June 2017

Academic Editor: R. Torrecillas

Copyright (C) 2017 Marcela Elisabeta Barbinta-Patrascu et al. This is an open access article distributed under the Creative Commons Attribution License, which permits unrestricted use, distribution, and reproduction in any medium, provided the original work is properly cited.

\begin{abstract}
In recent years, a considerable interest was paid to ecological strategies in management of plant diseases and plant growth. Metallic nanoparticles (MNPs) gained considerable interest as alternative to pesticides due to their interesting properties. Green synthesis of MNPs using plant extracts is very advantageous taking into account the fact that plants are easily available and eco-friendly and possess many phytocompounds that help in bioreduction of metal ions. In this research work, we phytosynthesized AgNPs from aqueous extract of Citrus reticulata peels, with high antioxidant, antibacterial, and antifungal potential. These "green" AgNPs were characterized by modern biophysical methods (absorption and FTIR spectroscopy, AFM, and zeta potential measurements). The nanobioimpact of Citrus-based AgNPs on four invasive wetland plants, Cattail (Typha latifolia), Flowering-rush (Butomus umbellatus), Duckweed (Lemna minor), and Water-pepper (Polygonum hydropiper), was studied by absorption spectroscopy, by monitoring the spectral signature of chlorophyll. The invasive plants exhibited different behavior under AgNP stress. Deep insights were obtained from experiments conducted on biomimetic membranes marked with chlorophyll $a$. Our results pointed out the potential use of Citrus-based AgNPs as alternative in controlling pathogens in aqueous media and in management of aquatic weeds growth.
\end{abstract}

\section{Introduction}

Since its invention in 1959 [1], nanotechnology became the most fascinating area of science. Nowadays, the progress in nanotechnology opened new perspectives of metal nanoparticles (MNPs) applications in agriculture, in plant diseases or plant growth management $[2,3]$. Among MNPs, silver nanoparticles (AgNPs) gained great popularity in various applications: biomedical, antimicrobial, antioxidant, antifungal, insecticidal, agriculture, and cosmetics industries [2, 411].

In last years, plant extracts were the most used resources in various fields: cosmetics [12], agriculture, and medicine [13], as environmentally benign inhibitor toward corrosion of carbon steel in acid media [14] or as precursor for biosynthesis of silver nanoparticles $[8,15-18]$. 
The increasing interest in plants is due to their high abundance in nature, recyclability, and their content rich in bioactive principles. Contrary to chemical synthesis of AgNPs, which used toxic agents, the "green" synthesis of nanosilver using plant extracts is preferred today because it uses eco-friendly chemicals and raw materials.

Our work aimed to study the application of phytosynthesized AgNPs using an aqueous extract of Citrus reticulata (tangerine or mandarin) peels in management of water pond quality and control of invasive aquatic weeds.

In order to get deep insights about the action of AgNPs, the tests were firstly conducted in vitro, on mimicking photosynthetic membranes (artificial lipid bilayers loaded with chlorophyll $a$ ).

The studies were further performed on four common Romanian wetland plants: Cattail (Typha latifolia), Flowering-rush (Butomus umbellatus), Duckweed (Lemna minor), and Water-pepper (Polygonum hydropiper). They are invasive plants that rapidly reproduce and invade habitats, displacing many native species. Although these plants give a beautiful landscape and constitute a nutritional source for waterfowl or other birds and also provide protection for different aquatic creatures, they can become harmful in certain situations, when invading irrigation systems, fish lakes, or swimming pools, with dramatic consequences on economy (disrupting hydropower generation; impairment of commercial and recreational navigation; interfering with safe swimming and with fishing; endangering human health and increasing drowning risk; impairing drinking water, etc.) and ecology (suppression of desirable native plants; reducing species diversity; water quality degradation; alteration of animal community interactions; fish killing, etc.) [20]. Uncontrolled growth of these invasive species can be stopped with pesticides, but these chemicals could be harmful for human health and the environment, too. So, novel methods, safer and environmental benign, must be imposed to overcome these problems. Thus, AgNPs biogenerated from C. reticulata peels extract (Citrus-nAg) were tested for application in controlling phytopathogens and invasive plants in aquatic media. Citrus-nAg were firstly characterized by spectral methods (absorption and FTIR spectroscopy), and morphological aspects were obtained from AFM investigations. The stability of Citrus-nAg was checked by zeta potential measurements. Further investigations on bioactivities of Citrus-nAg demonstrated their antioxidant, antibacterial, and antifungal properties. The bioimpact on the tested wetland plants was assayed by treating these herbs with increasing concentrations of Citrus-nAg and monitoring the spectral signature of chlorophyll (Chl).

\section{Materials and Methods}

2.1. Materials. Soybean lecithin (Calbiochem), $\mathrm{KH}_{2} \mathrm{PO}_{4}$, $\mathrm{Na}_{2} \mathrm{HPO}_{4}$, peptone, $\mathrm{HCl}, \mathrm{H}_{2} \mathrm{O}_{2}$, luminol (5-amino-2,3dihydrophthalazine-1,4-dione), and Tris (hydroxymethyl aminomethane base) were purchased from Merck (Germany). Silver nitrate $\left(\mathrm{AgNO}_{3}\right)$ was supplied by Gatt Koller$\mathrm{GmbH}$, Austria. $\mathrm{NaCl}, 69 \% \mathrm{HNO}_{3}$, and $37 \% \mathrm{HCl}$ were purchased from Sigma-Aldrich (Germany). The yeast extract was obtained from Biolife and the agar from Fluka.

Chlorophyll a (Chla) was obtained in our laboratory from fresh spinach (Spinacia oleracea L.) leaves by a chromatographic method as previously described [21, 22], and the purity of this phytopigment was checked by Vis absorption spectra.

\subsection{Sample Preparation}

2.2.1. Preparation of Citrus reticulata Peels' Extract. Fresh tangerine peels thoroughly washed with distilled water and dried with filter paper were cut into small pieces and then mixed with distilled water in a final mass ratio Citrus peels/distilled water of $1: 3(\mathrm{w} / \mathrm{w})$. The as-prepared mixture was boiled for 5 minutes. After cooling at room temperature and in dark, it was filtered with Whatman filter paper number 1 and then kept in freezer.

2.2.2. Biosynthesis of AgNPs from Citrus reticulata Peels' Extract (Citrus- $n A g$ ). An amount of $34 \mathrm{mg} \mathrm{AgNO}_{3}$ was added to $50 \mathrm{~mL}$ aqueous extract under continuously stirring at room temperature. The biosynthesis of nanosilver from C. reticulata peels' extract (named Citrus-nAg) was visually observed via color change of this mixture. Tangerine peel extract, which is eco-friendly, acted as both a reducing and a stabilizing agent.

\subsubsection{Preparation of Biomimetic Membranes Marked with} Chla. Small unilamellar vesicles (SUVs) labeled with Chla were prepared according to $[23,24]$, by hydrating a soybean lecithin/Chla (100:1, molar ratio) thin film with phosphate buffer ( $\mathrm{PB}, \mathrm{KH}_{2} \mathrm{PO}_{4}-\mathrm{Na}_{2} \mathrm{HPO}_{4} \mathrm{pH} 7.4$ ), followed by mechanical stirring (VIBRAX stirrer-OHIO 43230, USA, $200 \mathrm{rpm}, 40 \mathrm{~min}$ ), and then subjected to ultrasound treatment (Hielscher Ti probe sonicator, UP $100 \mathrm{H}$-Hielscher Ultrasonics GmbH, 14513 Teltow, Germany).

2.3. Characterization Methods. The absorption spectra were recorded in the $200-800 \mathrm{~nm}$ wavelength range on a double beam Lambda 2S Perkin Elmer UV-Vis spectrophotometer, operated at a resolution of $1 \mathrm{~nm}$.

The fluorescence emission spectra of Chla in biomimetic membranes were collected in the wavelength range of 600-800 nm, on a LS55 Perkin Elmer fluorescence spectrometer, by illuminating the samples with $430 \mathrm{~nm}$ excitation wavelength.

FTIR spectra of samples were obtained using a Fourier Transform Infrared Spectrophotometer (Tensor 37 from Bruker). For all of the scans, the spectra were collected in the wavenumber range of $400-4000 \mathrm{~cm}^{-1}$, at a spectral resolution of $4 \mathrm{~cm}^{-1}$.

The silver content in the AgNP suspension was determined by atomic absorption spectroscopy, AAS (ContrAA 700, Analytik Jena, Germany), after microwave assisted acid digestion (Milestone, SUA). In order to quantify the silver ion concentration released in time, the AgNP stock suspension was subjected to centrifugation $(21000 \times \mathrm{g}$ for 30 minutes, at $0^{\circ} \mathrm{C}$, SIGMA $2-16 \mathrm{~K}$ centrifuge) at different periods. All 
measurements were performed in triplicate. Prior to AAS analysis, approximately $0.5 \mathrm{~g}$ of each sample was completely digested using a mixture of $69 \% \mathrm{HNO}_{3}, 37 \% \mathrm{HCl}$, and $30 \%$ $\mathrm{H}_{2} \mathrm{O}_{2}$.

The morphology of silver nanoparticles was analyzed using an APE Research A100-SGS (Italy) atomic force microscope (AFM), working in contact mode system. Gwyddion software was used to process AFM images.

Zeta potential (ZP) measurement was carried out in an appropriate device of Zetasizer Nano ZS (Malvern Instruments Ltd., UK), by applying an electric field across the analyzed aqueous suspension.

The in vitro antioxidant activity (AA\%) of Citrus-nAg was assayed through chemiluminescence method on a Chemiluminometer Turner Design TD 20/20 (USA), by using the system containing: luminol $(1 \mathrm{mM})$, Tris- $\mathrm{HCl}$ buffer solution ( $\mathrm{pH} 8.6)$, and $\mathrm{H}_{2} \mathrm{O}_{2}(10 \mu \mathrm{M})$, as free radical generator. The value of $\mathrm{AA} \%$ was expressed as

$$
\mathrm{AA}=\left[\frac{\left(I_{0}-I\right)}{I_{0}}\right] \cdot 100 \%,
$$

where $I_{0}$ is the maximum CL intensity at $t=5 \mathrm{~s}$, for the reaction mixture without the sample, and $I$ is the maximum CL intensity for each sample, at $t=5 \mathrm{~s}$ [25].

For determination of Minimum Inhibitory Concentration (MIC value recorded is defined as the lowest concentration of the assayed antimicrobial agent that inhibits the visible growth of the microorganism tested, and it is usually expressed in $\mu \mathrm{g} / \mathrm{mL}$ ) of Citrus-nAg against the tested microbial strains, each of the tested microorganisms was determined by the broth dilution technique [26]. Serially diluted logarithmic concentrations of the Citrus-nAg ranging from $400 \mu \mathrm{g} / \mathrm{mL}$ to $0.195 \mu \mathrm{g} / \mathrm{mL}$ were inoculated with standardized overnight cultures of the microorganisms and incubated at $37^{\circ} \mathrm{C}$. Dilution methods are the most appropriate ones for the determination of MIC values, since they offer the possibility of estimating the concentration of the tested antimicrobial agent in the broth medium [27]. The most recognized standards are provided by the CLSI and the European Committee on Antimicrobial Susceptibility Testing (EUCAST) [28]. The MIC assay was performed in triplicate.

In order to evaluate the antibacterial activity, the CitrusnAg were tested against pathogenic Escherichia coli ATCC 8738 microbial strain. The bacterial strains were grown in Luria Bertani Agar (LBA) plates at $37^{\circ} \mathrm{C}$ with following composition: peptone $(10 \mathrm{~g} / \mathrm{L})$; yeast extract $(5 \mathrm{~g} / \mathrm{L}), \mathrm{NaCl}(5$ $\mathrm{g} / \mathrm{L})$; and agar $(20 \mathrm{~g} / \mathrm{L})$. The stock culture was maintained at $4^{\circ} \mathrm{C}$.

Antifungal activity of Citrus-nAg was tested against the fungal aquatic pathogen Fusarium oxysporum ATCC 48112. The stock culture was maintained at $4^{\circ} \mathrm{C}$. These strains were cultivated onto potato-dextrose agar (abbreviated "PDA") from Sigma-Aldrich Company with next composition: potato extract ( $4 \mathrm{~g} / \mathrm{L})$, dextrose $(20 \mathrm{~g} / \mathrm{L})$, and agar $(15 \mathrm{~g} / \mathrm{L})$.

Time-kill test is the most appropriate method for determining the bactericidal or fungicidal effect. The time-kill test reveals a time-dependent or a concentration-dependent antimicrobial effect $[28,29]$. For bacteria, this test has been well standardized and described in M26-A document of CLSI [30]. Similarly, several antifungal substances were studied by this method [31, 32].

Time-kill test for determining the bactericidal effect was performed in broth culture medium using three tubes containing a bacterial suspension of $5 \cdot 10^{5} \mathrm{CFU} / \mathrm{mL}$ (colonyforming units $/ \mathrm{mL}$ ). The first and the second tubes contain the extract tested usually at final concentrations of $0.25 \mathrm{MIC}$ and $1 \mathrm{MIC}$, and the third one is considered as the growth control. $1 \mathrm{~mL}$ of each tube was placed onto Bacto-Agar plates. The incubation was done under suitable conditions for $24 \mathrm{~h}$ at $37^{\circ} \mathrm{C}$ to determine the number of viable $E$. coli in terms of CFU. Then, the percentage of dead cells was calculated relatively to the growth control by determining the number of living cells $(\mathrm{CFU} / \mathrm{mL})$ of each tube using the agar plate count method [33].

Time-Kill Test for Determining the Fungicidal Effect. The agar dilution method involves the incorporation of varying desired concentrations ( $1 \mathrm{MIC}$ and $0.25 \mathrm{MIC}$ ) of the Citrus$\mathrm{nAg}$ into an agar medium, followed by the inoculation of a Fusarium oxysporum inoculum onto the agar plate surface. The plates were incubated for $4-5$ days at $37^{\circ} \mathrm{C}$ to see the fungicidal effect [34].

Standard deviation was calculated as the square root of variance using STDEV function in Excel 2010.

\section{Results and Discussion}

3.1. Characterization of Silver Nanoparticles Biosynthesized from Tangerine Peel Extract. The biosynthesis of silver nanoparticles from aqueous extract of C. reticulata peels was firstly monitored by visual inspection. Thus, after addition of silver ions, the color of tangerine extract turned from orange to dark brown (Figure 1).

The green synthesis of AgNPs was further confirmed by spectral characterization (Figure 2) and AFM analysis (Figure 3). The absorption spectra (Figure 2(a)) showed that, after adding silver nitrate to vegetal extract, a SPR band appeared at $443 \mathrm{~nm}$, which is characteristic for spherical/quasi-spherical silver nanoparticles $[8,35]$.

The FTIR transmission spectrum (Figure 2(b)) of aqueous $C$. reticulata extract showed presence of IR bands at 3850 , 3740 , and $3321 \mathrm{~cm}^{-1}$ (characteristic of $\mathrm{O}-\mathrm{H}$ stretching of hydroxyls), 2355 and $2112 \mathrm{~cm}^{-1}(\mathrm{~N}-\mathrm{H}$ stretching vibrations), $1740 \mathrm{~cm}^{-1}\left(\mathrm{C}=\mathrm{O} \mathrm{cm} \mathrm{cm}^{-1}\right.$ stretching attributed to aldehyde, ketones, carboxylic acid, or pectin ester), $1639 \mathrm{~cm}^{-1}$ (attributed to amide I; pectin), $1368 \mathrm{~cm}^{-1}$ (C-CH3 bending), $1218 \mathrm{~cm}^{-1}$ (C-O stretch acidic or $\nu_{\text {as }}(\mathrm{C}-\mathrm{O}-\mathrm{C})$ of geranyl acetate (acyclic monoterpene) ), $1110 \mathrm{~cm}^{-1}$ ( $\nu(\mathrm{CO}), v(\mathrm{CC})$ ring of polysaccharides, and pectin), $1082 \mathrm{~cm}^{-1}$ and $1068 \mathrm{~cm}^{-1}$ (may be due to alcohol, carboxylic acid and esters), and 641 $\mathrm{cm}^{-1}$ (assigned to bending modes of aromatic compounds) $[11,15,36-38]$.

After bioreduction of silver ions, the following events were observed:

(1) The FTIR bands at $3850,3740,1740$, and $1639 \mathrm{~cm}^{-1}$ were shifted to $3857,3743,1747$, and $1633 \mathrm{~cm}^{-1}$, 


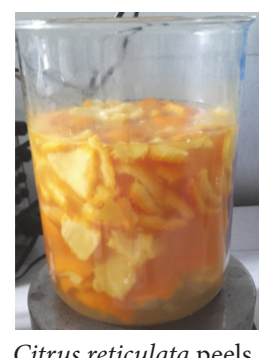

Citrus reticulata peels (in distilled water)
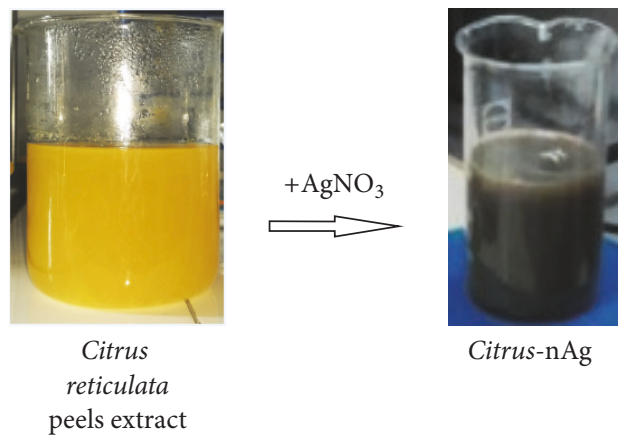

FIGURE 1: Schematic representation of AgNPs biosynthesis from Citrus reticulata peels extract.

respectively, becoming strong and sharps (3857 and $3743 \mathrm{~cm}^{-1}$ ) and weaker $\left(1747\right.$ and $1633 \mathrm{~cm}^{-1}$ ).

(2) The peaks at 3857 and 3743 are more strong and sharp, while that at $1633 \mathrm{~cm}^{-1}$ weakened.

(3) The band at $1068 \mathrm{~cm}^{-1}$ shifted to $1060 \mathrm{~cm}^{-1}$ and became stronger in AgNP spectrum.

(4) New peak was observed in the FTIR spectrum of Citrus-nAg: $2927 \mathrm{~cm}^{-1}$ (alkyls C-H stretching) [39].

On the other hand, both Citrus extract and AgNPs presented broad strong FTIR peaks at 3321 and $3384 \mathrm{~cm}^{-1}$, respectively, suggesting the presence of stretch hydrogen bonding. It could be observed from the FTIR spectra of Citrus reticulata peels extract and of Citrus-nAg that hydroxyl and carboxyl groups are predominant.

Our IR results confirmed that phytomolecules like pectin, polyphenols, and proteins played an important role in the bioreduction of silver ions, these biomolecules acting as both reducing and capping agents for silver nanoparticles.

The physical stability of AgNPs was evaluated in terms of zeta potential measurements, via their electrophoretic mobility in an electric field [40]. The obtained ZP value showed that the "green" synthesized AgNPs are quite stable (ZP = $-21.9 \mathrm{mV}$ ), their physical stability being achieved through interparticle repulsion forces, due to the presence onto their surface, of the carboxyl groups arising from Citrus reticulata peels extract (see Figure 2(b)).

Few drops of Citrus-nAg suspension were deposited on a silica glass plate and allowed to dry at room temperature in the dark, and then the resulting thin film was analyzed by AFM. Figure 3 illustrates the morphological aspects in three-dimensional AFM image (a) and line profile (b) of Citrus-nAg. As observed, spherical silver nanoparticles with nanoscaled dimension (mean diameter $<135 \mathrm{~nm}$ ) and good dispersion were obtained by a green route from tangerine peels. The shape of AgNPs was firstly predicted by absorption spectrum and then confirmed by AFM analysis. The average roughness (the arithmetic average texture of one surface) provided by AFM images was $R_{a}=28.4 \mathrm{~nm}$, and the root mean square parameter $\left(R_{\mathrm{ms}}\right)$ reached the value of $36.6 \mathrm{~nm}$.

The AAS results indicated that the concentration of AgNP stock suspension was $538.3 \mathrm{ppm}$. The high toxicity of silver ions is well known [41], that is why the silver content was determined in the supernatants (which contain silver ions) of the Citrus-nAg suspensions taken at different times after Citrus-nAg preparation.

The supernatants collected one hour and five hours after addition of silver nitrate to tangerine extract contained silver in concentration of 191.1 and $92.4 \mathrm{ppm}$, respectively, indicating that the silver bioreduction was not finished after $5 \mathrm{~h}$, and $\mathrm{Ag}^{+}$was still present in suspension. On the contrary, the silver content was $0 \mathrm{ppm}$ in the supernatants collected after 1 , 2, 3, and 7 days, indicating that $\mathrm{Ag}^{+}$was not present in any supernatant, the Citrus-nAg being stable even after 7 days.

3.2. The Bioactivities of Citrus-nAg. The in vitro antioxidant activity assay revealed high potential of Citrus-nAg of free radical scavenging, through chemiluminescence method. Their antioxidant activity reached the value of $98.5 \%$. Two main factors are responsible for this strong antioxidant potential:

(1) the presence of antioxidant biomolecules (like polyphenols, pectin, etc.) coming from tangerine peel extract (see Figure 2(b)) as capping agents of AgNPs [42];

(2) the nanodimensions of Citrus-nAg (Figure 3), which offer high total surface area providing many reaction centres that improve the free radical scavenging capacity $[8,43]$.

As known, usual microbial contaminants of aquatic media are Escherichia coli and Fusarium oxysporum, which can cause severe diseases [44-48], especially to the immunocompromised hosts [49] so the antimicrobial investigations were conducted on E.coli ATCC 8738 bacterium and Fusarium oxysporum ATCC 48112 fungus.

Results obtained for the antimicrobial susceptibility test of Citrus-nAg on the organism showed MIC of $25 \pm 0.19$ and $12.5 \pm 0.13 \mu \mathrm{g} / \mathrm{mL}$ against Escherichia coli and Fusarium oxysporum, respectively (see Table 1).

Antimicrobial susceptibility was determined on 3 different days, and MIC values for each isolate were reported as the median of 3 experiments.

The C. reticulate-based AgNPs exhibited strong antibacterial activity against E.coli ATCC 8738 (Figure 4). On the plate corresponding to the Citrus-nAg, 1 MIC $(25 \mu \mathrm{g} / \mathrm{mL})$, E. coli 


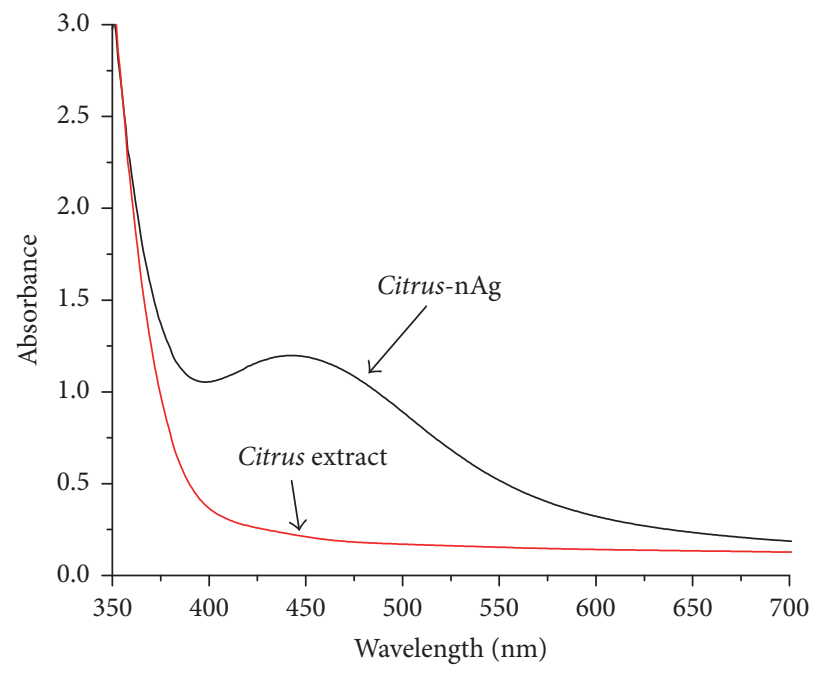

(a)
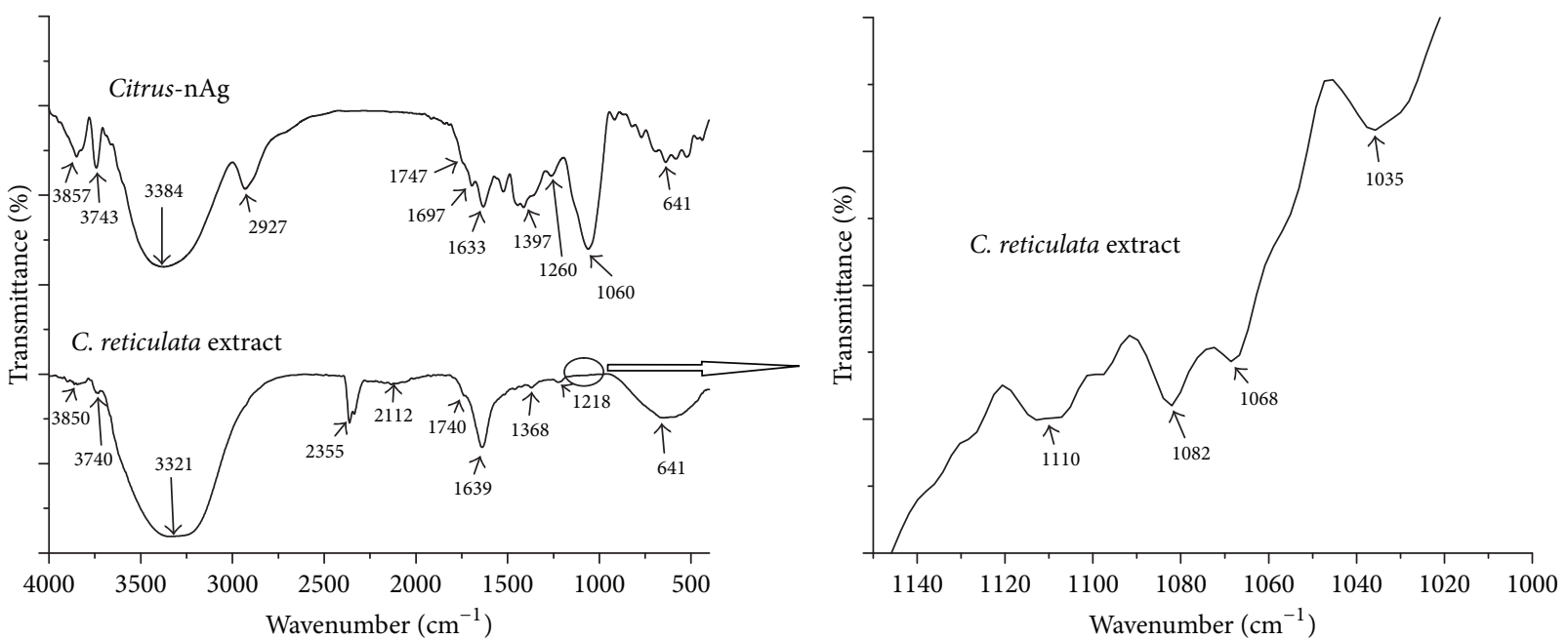

(b)

FIGURE 2: Comparative spectral characterization of aqueous C. reticulata extract and Citrus-nAg by (a) absorption and (b) FTIR spectroscopy.

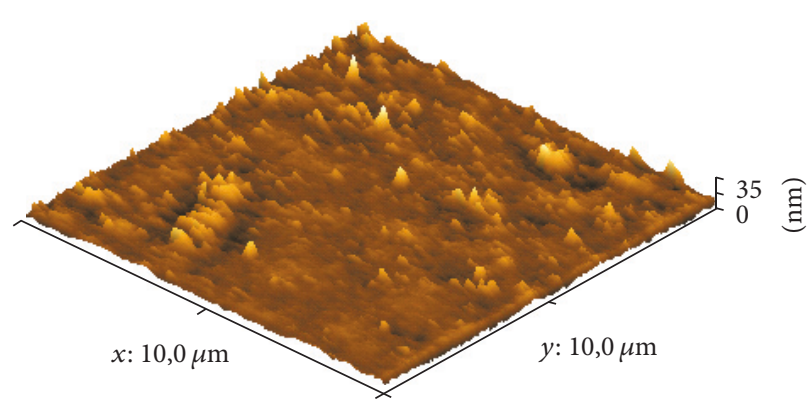

(a)

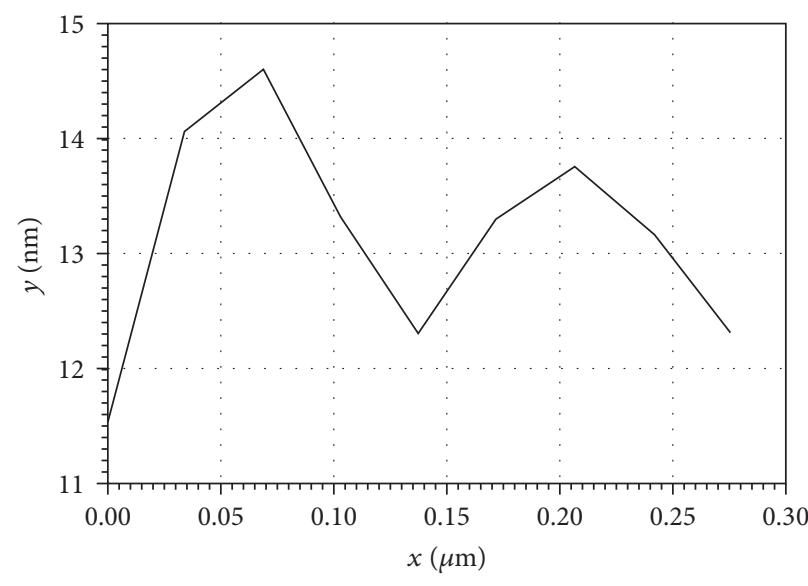

(b)

FIGURE 3: Three-dimensional AFM image (a) and line profile (b) of Citrus-nAg. 
TABLE 1: Antimicrobial susceptibility of the microorganisms to Citrus-nAg.

\begin{tabular}{lcccccccccccc}
\hline \multirow{2}{*}{ Microorganism } & \multicolumn{10}{c}{ Concentration of Citrus-nAg used $(\mu \mathrm{g} / \mathrm{mL})$} \\
& 400 & 200 & 100 & 50 & 25 & 12.5 & 6.25 & 3.125 & 1.56 & 0.78 & 0.39 & 0.195 \\
\hline Escherichia coli & $\mathrm{S}$ & $\mathrm{S}$ & $\mathrm{S}$ & $\mathrm{S}$ & $\mathrm{S}$ & $\mathrm{R}$ & $\mathrm{R}$ & $\mathrm{R}$ & $\mathrm{R}$ & $\mathrm{R}$ & $\mathrm{R}$ & $\mathrm{R}$ \\
Fusarium oxysporum & $\mathrm{S}$ & $\mathrm{S}$ & $\mathrm{S}$ & $\mathrm{S}$ & $\mathrm{S}$ & $\mathrm{S}$ & $\mathrm{R}$ & $\mathrm{R}$ & $\mathrm{R}$ & $\mathrm{R}$ & $\mathrm{R}$ & $\mathrm{R}$ \\
\hline
\end{tabular}

Note. R: resistant; S: susceptible/sensitive.

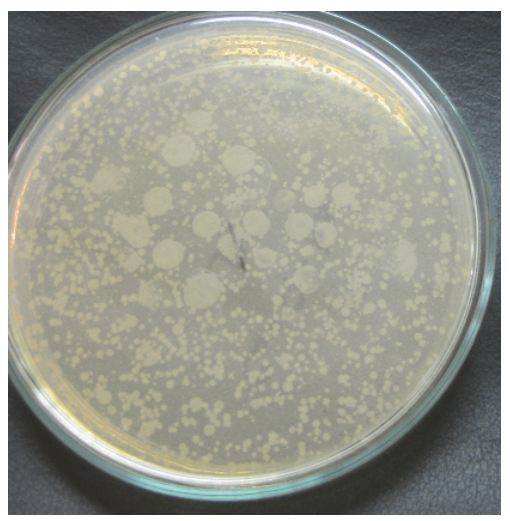

(a)

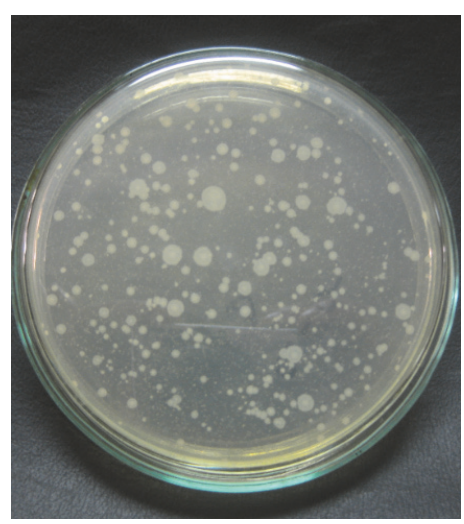

(b)

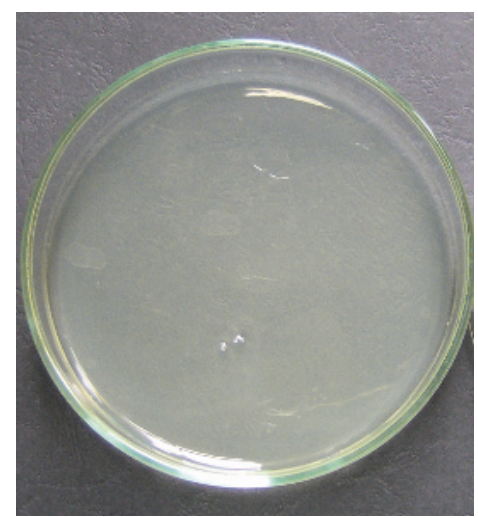

(c)

Figure 4: Bacto-Agar plates with CFU of E. coli to determine the Time-kill (concentration-dependent antimicrobial effect) of (a) growth control, (b) Citrus-nAg, 0.25 MIC, and (c) Citrus-nAg, 1 MIC.

culture was inhibited ( $0 \mathrm{CFU} / \mathrm{mL}$ of $E$. coli), confirming the antibacterial effect of this sample (Figure 4(c)). In the plates corresponding to the Citrus-nAg, 0.25 MIC $(6.25 \mu \mathrm{g} / \mathrm{mL})$, a more pronounced growth of E. coli was noticed $\left(248 \cdot 10^{3} \pm\right.$ $0.22 \mathrm{CFU} / \mathrm{mL}$ ).

This microbial response is due to the presence on the AgNP surface of the capping biomolecules arising from $C$. reticulata peels (see Figure $2(\mathrm{~b})$ ), which have antibacterial properties (pectin, flavonoids, etc.). As observed, Citrus-nAg has great potential for application as disinfectant for pools, ponds, or different aquatic basins.

The antifungal activity investigation of the biogenerated AgNPs was performed as previously described (see Section 2.3). Fungicidal activity of Citrus-nAg against Fusarium oxysporum ATCC 48112, a commonly occurring fungal aquatic pathogen, is illustrated in Figure 5.

Citrus-AgNPs showed a significant effect on morphological structure of this fungus (Figure 6(b)); it induced important changes in the macroscopic appearance of fungal colonies (near halo) and the colonies appeared white and adherent to the surface of the medium. In most cases, the addition of Citrus-nAg led to smaller colonies and partial loss of spore formation (see as colorless colonies).

Light microscopic observation on Fusarium oxysporum hyphae exposed to AgNPs revealed considerable morphological alterations in hyphae; these appeared degraded and large vesicles are also visible.

Light microscopy of untreated fungi revealed normal mycelia; however hyphae of the strains grown on media with Citrus-nAg revealed alterations in the morphology of the hyphae and in the sporulation process.
The antifungal activity of these silver nanoparticles is maybe due to their capacity of anchoring to the surface of fungal cells destructing the membrane integrity [50], which caused the cell death. Another key factor responsible for this antifungal ability of Citrus-nAg is the presence of phytomolecules (flavonoids, pectin, volatile oils, etc.), arising from Citrus reticulata peels extract, as capping agents for Citrus$\mathrm{nAg}$, with fungicide properties [51-53].

3.2.1. The Impact of Citrus-nAg on Biomimetic Membranes. In order to get more information (at molecular level) about the action of Citrus-nAg on the wetland plants, we firstly studied the influence of these nanosilver particles on mimicking cell membranes, because the biomembranes are the first target for any stressor. Increasing concentrations of Citrus$\mathrm{nAg}$ were added to a suspension of biomimetic membranes marked with Chla, which were characterized by absorption and emission spectroscopy (Figure 7). Chla acted as a spectral marker that detects the changes occurring in artificial lipid bilayers. It was observed that the height of the red absorption peak (Figure 7(a)) was reduced under AgNP stress.

Chla fluorescence quenching occurred in Citrus-nAgstressed biomimetic membranes (Figure 7(b)), action that is possible due to an electron-transfer or an energy-transfer process when the fluorophore, which is the porphyrin ring of chlorophyll, attached directly to the surface of AgNPs [54,55].

3.2.2. The Bioimpact of Citrus-nAg on Wetland Plants. The effects of Citrus-nAg on four native wetland plants, Typha latifolia, Butomus umbellatus, Lemna minor, and Polygonum 


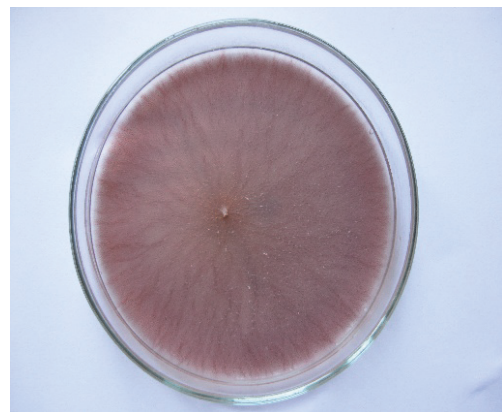

(a)

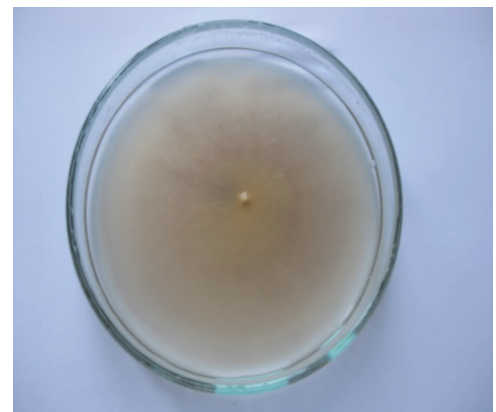

(b)

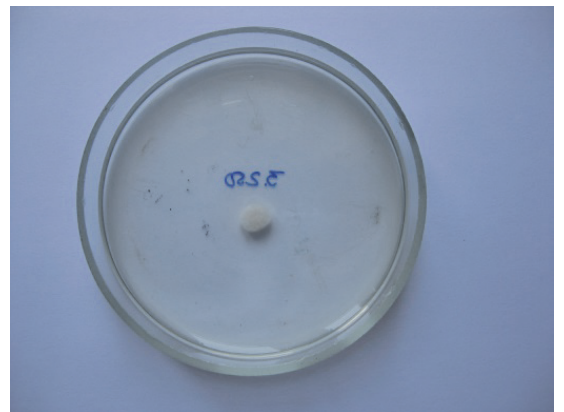

(c)

Figure 5: Agar plates with Fusarium oxysporum to determine the Time-kill (concentration-dependent antimicrobial effect) of (a) growth control, (b) Citrus-nAg, 0.25 MIC, and (c) Citrus-nAg, 1 MIC.

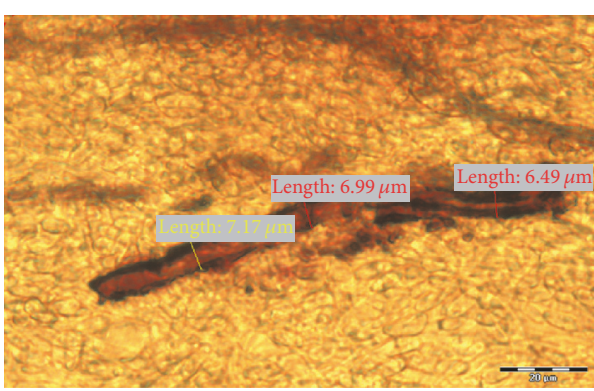

(a)

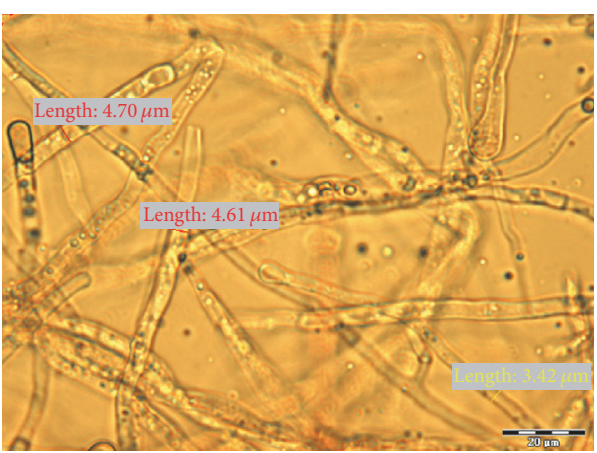

(b)

FIGURE 6: The microscopic aspect of reproductive formations for Fusarium oxysporum: (a) before and (b) after treatment with Citrus-nAg (scale of $20 \mu \mathrm{m}$ ).

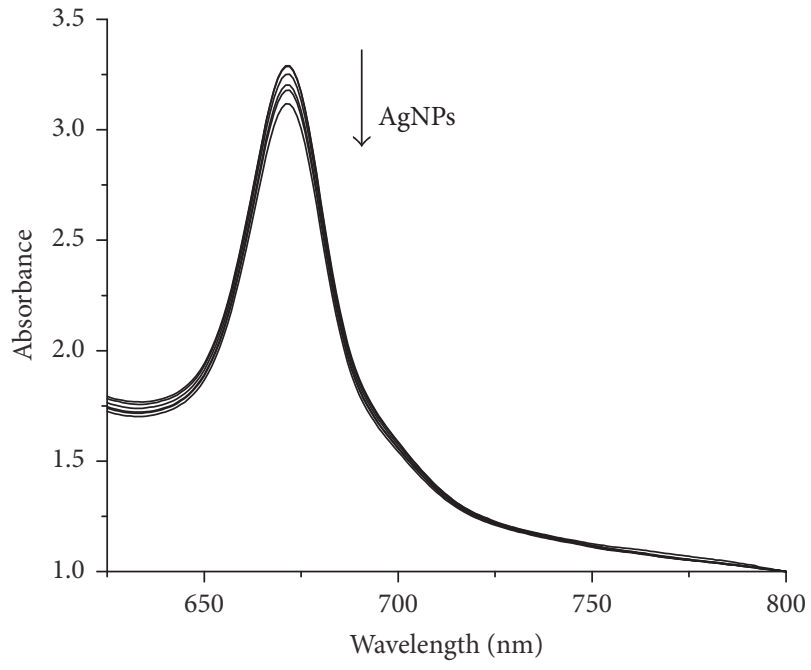

(a)

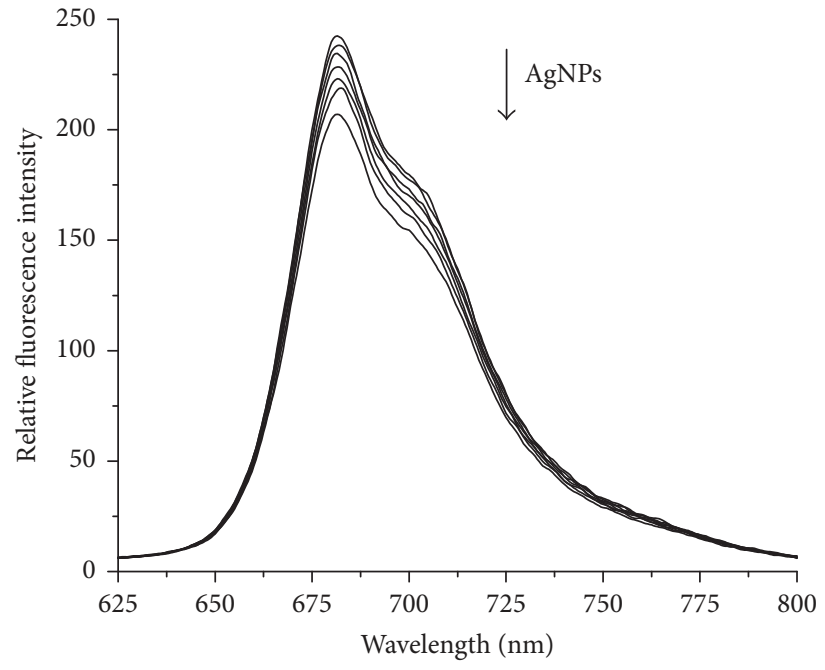

(b)

FIGURE 7: Spectral monitoring of AgNP effects on biomimetic membranes marked with Chla: the absorption (a) and the fluorescence emission (b) spectra. The absorption spectra were corrected for the contribution of light scattering as described in [19] and normalized at $800 \mathrm{~nm}$. In the fluorescence experiments, the excitation wavelength was $430 \mathrm{~nm}$. 


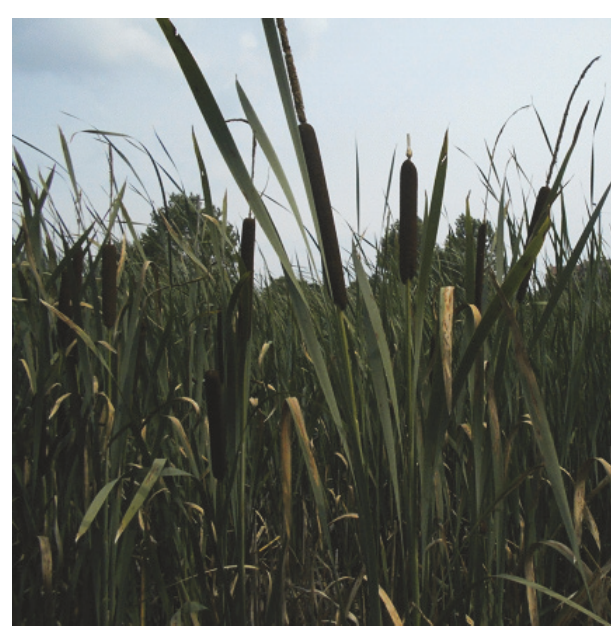

Rush, cattail

(Typha latifolia)

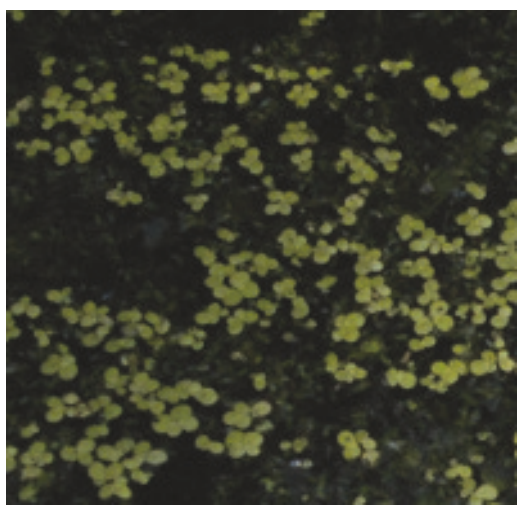

Duckweed

(Lemna minor)

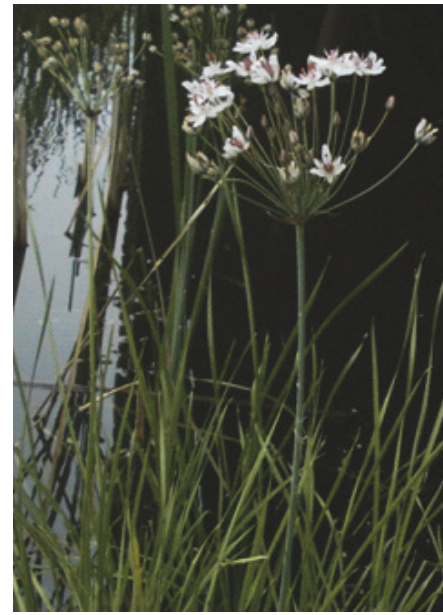

Flowering-rush

(Butomus umbellatus)

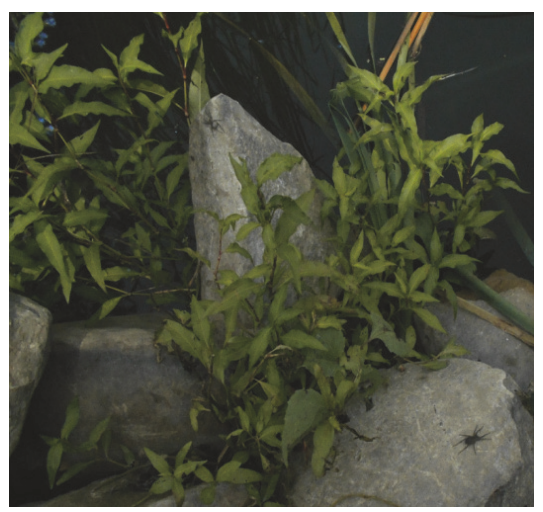

Water-pepper

(Polygonum hydropiper)

Figure 8: The images of the four native wetland plants: Typha latifolia, Butomus umbellatus, Lemna minor, and Polygonum hydropiper studied in this work.

hydropiper (Figure 8), were studied. These plants were collected from a natural lake in a park from Oltenita, a Romanian city.

The plants (about two months aged) were treated with increasing concentrations of Citrus-nAg $(0.42,0.84,1.675$, $3.35,6.7,13.4,26.8$, and $53.5 \mathrm{ppm}$ ) and then visually monitored for two weeks. No significant alterations of herbals were observed with the naked eye at Citrus-nAg concentrations less than $13.4 \mathrm{ppm}$. In all cases, the concentration of $13.4 \mathrm{ppm}$ was critical, because at this concentration of AgNPs, visible modifications on plant morphology could be observed. At concentrations greater than $13.4 \mathrm{ppm}$, the plants were died. Flowering-rush and Water-pepper were the most sensitive: they started withering after four days of AgNPs-stress. On the contrary, the rush withered just after two weeks. Duckweed was the most resistant; in this case, visible modifications were observed only at AgNP concentration greater than $13.4 \mathrm{ppm}$.

These visual observations were further confirmed by spectral characterization of the vegetal extracts prepared by shredding the leaves of each wetland plants, in distilled water (the mass ratio leaves/water was 1:10). In this respect, we compared the absorption spectra of the extracts prepared from AgNPs (13.4 ppm)-stressed plants with that of untreated ones (Figure 9).

Chlorophyll (Chl) was chosen as an indicator of plant quality. Chl is a key molecule in photosynthesis and plays a vital role for higher plants surviving. The level of $\mathrm{Chl}$ is an indicator of physiological status of plants, any change of Chl absorption or Chl fluorescence reflecting the level of photosynthesis [56].

Monitoring the absorption band at the main red peak of Chls, which is a spectral signature of these porphyrins, a decline of this band was observed and hence a decrease in chlorophyll content after $\mathrm{nAg}$ stress. This process was also observed in the previous assay performed on biomimetic membranes (see Figure 7). The intensity of the main red peak characteristic for Chl decreased under nAg stress, but in the case of Butomus umbellatus, this band disappeared.

Similar behavior was found by Miao and coworkers [57], which observed a reduction of plant growth, photosynthesis, 

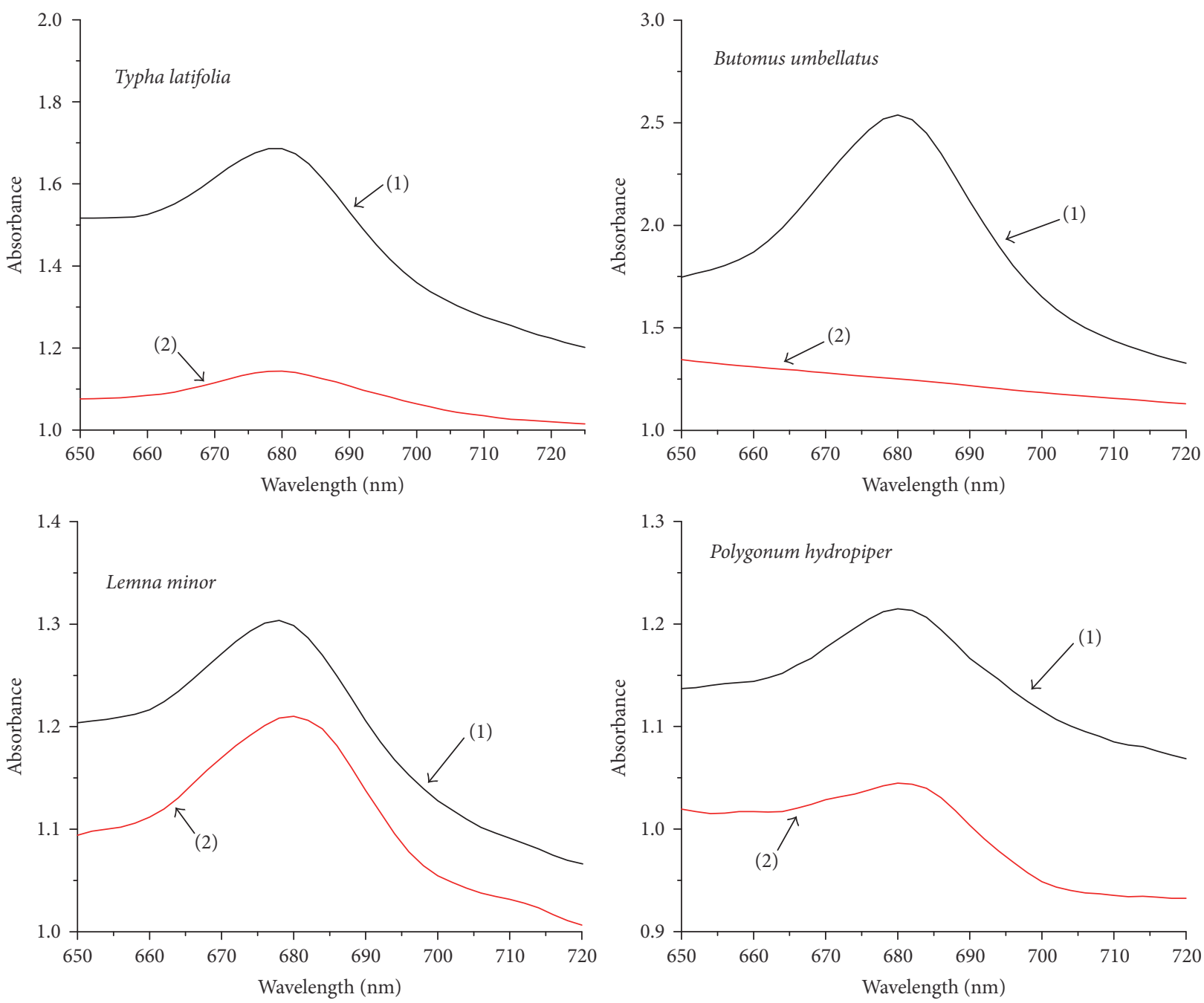

Figure 9: The absorption spectra of the wetland plant extracts: before (1) and after (2) treatment with Citrus-nAg (13.4 ppm).

and chlorophyll production in algae after AgNP treatment. Barbasz et al. highlighted that MNPs significantly affected the physiological properties of plants [58].

In our work, the bioimpact of Citrus-nAg on wetland plants was more pronounced in the case of Butomus umbellatus and nonsignificant in the case of Lemna minor. These findings are in accordance with our visual observations and with the experiments on artificial cell membranes (Figure 7).

Based on these results, we can concluded that Citrus-nAg enter into cell membranes and could induce physiological changes in plants (in a dose-dependent manner), by altering also the chlorophyll content.

\section{Conclusions}

An eco-friendly method was employed to biogenerate nanosilver, by using the aqueous extract of Citrus reticulata peels that proved to be very good bioreductant of silver ions for the synthesis of AgNPs. The biosynthesized AgNPs exhibited strong antimicrobial activity against Fusarium oxysporum ATCC 48112 fungus and Escherichia coli ATCC 8738 bacterium and also high antioxidant capacity.
The bioeffect of Citrus-nAg on four living wetland plants (Typha latifolia, Butomus umbellatus, Lemna minor, and Polygonum hydropiper) was studied through both in vivo and in vitro assays, by choosing the natural photopigment, chlorophyll, as an indicator of plant quality. A dose-dependent effect of AgNPs on the tested plants was observed. Furthermore, the optical signature of chlorophyll embedded in biomimetic membranes offered useful information about Citrus-nAg stress, at molecular level. The exposure to Citrus-nAg at an appropriate concentration could only sanitize the aquatic basins, keeping intact the weed flora. But in certain concentrations, these AgNPs could kill even the invasive plants.

The use of phytosynthesized AgNPs in aquatic media is a safer procedure, because the capping agents are biogenic and benign for environment.

Our results suggest that this "green" nanosilver biogenerated from aqueous extract of Citrus reticulata peels could be used in fabrication of eco-friendly disinfectants to fight against fungi and bacteria in wet media (swimming pools, shower drainages, SPA retreats, water filters, wetlands, etc.) and also in herbicidal nanoformulations to manage and keep under control the invasive aquatic plants. 


\section{Conflicts of Interest}

The authors declare that there are no conflicts of interest regarding the publication of this paper.

\section{Acknowledgments}

This work was cofinanced from the European Social Fund through the Sectorial Operational Programme Human Resources Development 2007-2013, Contract Code: POSDRU/187/ $1.5 / \mathrm{S} / 155559$, multidisciplinary doctoral research on European competitiveness (CdocMD) (M. Constantin). S. M. Iordache acknowledges research support provided under UEFISCDI Ctr. no. 142/2014 and Ctr. no. 46/2014.

\section{References}

[1] M. K. Sarmast and H. Salehi, "Silver Nanoparticles: An Influential Element in Plant Nanobiotechnology," Molecular Biotechnology, pp. 1-9, 2016.

[2] A. D. Servin and J. C. White, "Nanotechnology in agriculture: Next steps for understanding engineered nanoparticle exposure and risk," NanoImpact, vol. 1, pp. 9-12, 2016.

[3] M. R. Khan and T. F. Rizvi, "Nanotechnology: Scope and Application in Plant Disease Management," Plant Pathology Journal, vol. 13, no. 3, pp. 214-231, 2014.

[4] P. A. De León-Martínez, F. Soriano-Corral, C. A. Ávila-Orta et al., "Surface Modification of $\mathrm{nTiO}_{2} / \mathrm{Ag}$ Hybrid Nanoparticles Using Microwave-Assisted Polymerization in the Presence of Bis(2-hydroxyethyl) Terephthalate," Journal of Nanomaterials, vol. 2017, Article ID 7079497, pp. 1-9, 2017.

[5] J. Pulit-Prociak and M. Banach, "Silver nanoparticles-a material of the future...?" Open Chemistry, vol. 14, no. 1, pp. 76-91, 2016.

[6] G. A. M. Abdelmalek and T. A. Salaheldin, "Silver Nanoparticles as a Potent Fungicide for Citrus Phytopathogenic Fungi," Journal of Nanomedicine Research, vol. 3, no. 5, 8 pages, 2016.

[7] M. E. Barbinta-Patrascu, N. Badea, C. Pirvu et al., "Multifunctional soft hybrid bio-platforms based on nano-silver and natural compounds," Materials Science and Engineering C, vol. 69, pp. 922-932, 2016.

[8] M. E. Barbinta-Patrascu, N. Badea, C. Ungureanu, M. Constantin, C. Pirvu, and I. Rau, "Silver-based biohybrids "green" synthesized from Chelidonium majus L.," Optical Materials, vol. 56, pp. 94-99, 2016.

[9] M. A. Franco-Molina, E. Mendoza-Gamboa, D. G. ZarateTriviño et al., "In Vitro evaluation of colloidal silver on immune function: antilymphoproliferative activity," Journal of Nanomaterials, vol. 2016, 8 pages, 2016.

[10] S. Mishra and H. B. Singh, "Biosynthesized silver nanoparticles as a nanoweapon against phytopathogens: exploring their scope and potential in agriculture," Applied Microbiology and Biotechnology, vol. 99, no. 3, pp. 1097-1107, 2014.

[11] H. P. Borase, C. D. Patil, R. B. Salunkhe, C. P. Narkhede, B. K. Salunke, and S. V. Patil, "Phyto-Synthesized Silver Nanoparticles: A Potent Mosquito Biolarvicidal Agent," Journal of Nanomedicine Biotherapeutic Discovery, vol. 3, no. 1, pp. 104172, 2013.

[12] A. Ribeiro, M. Estanqueiro, M. Oliveira, and J. Sousa Lobo, "Main Benefits and Applicability of Plant Extracts in Skin Care Products," Cosmetics, vol. 2, no. 2, pp. 48-65, 2015.
[13] A. Giordano and A. Costs, Eds., Plant extracts: role in agriculture, health effects and medical applications (botanical research and practices), vol. 14, Nova Science Pub Inc, 1st edition, 2013.

[14] A. Cojocaru, I. Maior, D.-I. Vaireanu, I. Lingvay, C. Lingvay, and S. Caprarescu, "Estimation of inhibition efficiency for carbon steel corrosion in acid media by using natural plant extracts," Revista de Chimie, vol. 60, no. 11, pp. 1175-1180, 2009.

[15] M. E. Barbinta-Patrascu, I.-R. Bunghez, S. M. Iordache, N. Badea, R.-C. Fierascu, and R. M. Ion, "Antioxidant properties of biohybrids based on liposomes and sage silver nanoparticles," Journal of Nanoscience and Nanotechnology, vol. 13, no. 3, pp. 2051-2060, 2013.

[16] M. E. Barbinta-Patrascu, C. Ungureanu, S. M. Iordache et al., "Eco-designed biohybrids based on liposomes, mint-nanosilver and carbon nanotubes for antioxidant and antimicrobial coating," Materials Science and Engineering C, vol. 39, no. 1, pp. 177185, 2014.

[17] S. Roy and T. K. Das, "Plant mediated green synthesis of silver nanoparticles-a review," International Journal of Plant Biology and Research, vol. 3, no. 3, pp. 1044-1055, 2015.

[18] F. E. Meva, C. O. Ebongue, S. V. Fannang et al., "Natural Substances for the Synthesis of Silver Nanoparticles against Escherichia coli: The Case of Megaphrynium macrostachyum (Marantaceae), Corchorus olitorus (Tiliaceae), Ricinodendron heudelotii (Euphorbiaceae), Gnetum bucholzianum (Gnetaceae), and Ipomoea batatas (Convolvulaceae)," Journal of Nanomaterials, vol. 2017, Article ID 6834726, 6 pages, 2017.

[19] M. B. Patrascu, L. Tugulea, A. Meghea, and A. Popescu, "Oxidative stress on liposomes with chlorophylla monitored by spectral studies," Optoelectronics and Advanced Materials Rapid Communications, vol. 2, no. 2, pp. 113-116, 2008.

[20] L. A. Gettys, W. T. Haller, and D. G. Petty, Eds., Biology and Control of Aquatic Plants: A Best Management Practices Handbook, Aquatic Ecosystem Restoration Foundation, Wisconsin, USA, 3rd edition, 2014.

[21] H. H. Strain and W. A. Svec, "Extraction, separation, estimation, and isolation of the chlorophylls," in The Chlorophylls, L. P. Vernon and G. R. Seely, Eds., pp. 21-66, Academic Press, New York, NY, USA, 1966.

[22] M. E. Barbinta-Patrascu, N. Badea, L. G. Ţugulea, M. Giurginca, and A. Meghea, "Oxidative stress simulation on artificial membranes- chemiluminescent studies," Revista de Chimie, vol. 59, no. 8, pp. 834-837, 2008.

[23] M. E. Barbinta Patrascu, L. Tugulea, and A. Meghea, "Procaine effects on model membranes with chlorophylla," Revista de Chimie, vol. 60, no. 4, pp. 337-341, 2009.

[24] S. M. Milenkovic, M. E. Bărbînţă-Pătraşcu, G. Baranga, D. Z. Markovic, and L. Țugulea, "Comparative spectroscopic studies on liposomes containing chlorophyll a and chlorophyllide a," General Physiology and Biophysics, vol. 32, no. 4, pp. 559-567, 2013.

[25] I. Lacatusu, N. Badea, R. Stan, and A. Meghea, "Novel bio-active lipid nanocarriers for the stabilization and sustained release of sitosterol," Nanotechnology, vol. 23, no. 45, Article ID 455702, 2012.

[26] NCCLS M7-A6, "Methods for Dilution Antimicrobial Susceptibility. Test for Bacteria that Grow Aerobically," in Test for Bacteria that Grow Aerobically, 6th edition, 2003.

[27] W. B. Hugo and A. D. Russel, Pharmaceutical Microbiology, Blackwell science, London, UK, 6th edition, 1998.

[28] M. A. Pfaller, D. J. Sheehan, and J. H. Rex, "Determination of Fungicidal Activities against Yeasts and Molds: Lessons Learned 
from Bactericidal Testing and the Need for Standardization," Clinical Microbiology Reviews, vol. 17, no. 2, pp. 268-280, 2004.

[29] L. Esteban-Tejeda, K. Zheng, C. Prado et al., "Bone tissue scaffolds based on antimicrobial SiO2-Na2O-Al2O3-CaO-B2O3 glass," Journal of Non-Crystalline Solids, vol. 432, pp. 73-80, 2016.

[30] CLSI, Methods for Determining Bactericidal Activity of Antimicrobial Agents. Approved Guideline, CLSI document M26-A, Clinical and Laboratory Standards Institute, Pennsylvania, USA, 1998.

[31] C. J. Clancy, H. Huang, S. Cheng, H. Derendorf, and M. H. Nguyen, "Characterizing the effects of caspofungin on Candida albicans, Candida parapsilosis, and Candida glabrata isolates by simultaneous time-kill and postantifungal-effect experiments," Antimicrobial Agents and Chemotherapy, vol. 50, no. 7, pp. 25692572, 2006.

[32] M. E. Klepser, E. J. Ernst, R. E. Lewis, M. E. Ernst, and M. A. Pfaller, "Influence of test conditions on antifungal time-kill curve results: Proposal for standardized methods," Antimicrobial Agents and Chemotherapy, vol. 42, no. 5, pp. 1207-1212, 1998.

[33] M. Balouiri, M. Sadiki, and S. K. Ibnsouda, "Methods for in vitro evaluating antimicrobial activity: a review," Journal of Pharmaceutical Analysis, vol. 6, no. 2, pp. 71-79, 2016.

[34] CLSI, "Methods for Antimicrobial Dilution and Disk Susceptibility of Infrequently Isolated or Fastidious Bacteria, Approved Guideline, CLSI document M45-A2," 2nd., Ed., Clinical and Laboratory Standards Institute, Pennsylvania, USA, 2010.

[35] W. Raut Rajesh, R. Lakkakula Jaya, S. Kolekar Niranjan, D. Mendhulkar Vijay, and B. Kashid Sahebrao, "Phytosynthesis of silver nanoparticle using Gliricidia sepium (Jacq.)," Current Nanoscience, vol. 5, no. 1, pp. 117-122, 2009.

[36] J. Ord, H. J. Butler, M. R. McAinsh, and F. L. Martin, "Spectrochemical analysis of sycamore (Acer pseudoplatanus) leaves for environmental health monitoring," Analyst, vol. 141, no. 10, pp. $1-8,2016$.

[37] S. Kaviya, J. Santhanalakshmi, B. Viswanathan, J. Muthumary, and K. Srinivasan, "Biosynthesis of silver nanoparticles using Citrus sinensis peel extract and its antibacterial activity," Spectrochimica Acta-Part A: Molecular and Biomolecular Spectroscopy, vol. 79, no. 3, pp. 594-598, 2011.

[38] M. Torab-Mostaedi, "Biosorption of lanthanum and cerium from aqueous solutions using tangerine (Citrus reticulata) peel: equilibrium, kinetic and thermodynamic studies," Chemical Industry and Chemical Engineering Quarterly, vol. 19, no. 1, pp. 79-88, 2013.

[39] K. R. Namasivayam, R. S. A. Bharani, and M. R. Ansari, "Natural Occurrence of Potential Fungal Biopesticide Nomuraea Rileyi (Farlow) Samson Associated with Agriculture Fields of Tamil Nadu, India and its Compatibility with Metallic Nanoparticles," Journal of Biofertilizers Biopesticides, vol. 4, no. 1, pp. 132-139, 2013.

[40] P. R. Mishra, L. A. Shaal, R. H. Müller, and C. M. Keck, "Production and characterization of Hesperetin nanosuspensions for dermal delivery," International Journal of Pharmaceutics, vol. 371, no. 1-2, pp. 182-189, 2009.

[41] X. Yang, A. P. Gondikas, S. M. Marinakos et al., "Mechanism of silver nanoparticle toxicity is dependent on dissolved silver and surface coating in Caenorhabditis elegans," Environmental Science \& Technology, vol. 46, no. 2, pp. 1119-1127, 2012.

[42] A. M. Rincón, A. M. Vásquez, and F. C. Padilla, "Chemical composition and bioactive compounds of flour of orange
(Citrus sinensis), tangerine (Citrus reticulata) and grapefruit (Citrus paradisi) peels cultivated in Venezuela," Archivos Latinoamericanos de Nutrición, vol. 55, no. 3, pp. 305-310, 2005.

[43] P. N. Navya and H. K. Daima, "Rational engineering of physicochemical properties of nanomaterials for biomedical applications with nanotoxicological perspectives," Nano Convergenc, vol. 3, no. 1, pp. 1-14, 2016.

[44] V. Edel-Hermann, M. Sautour, N. Gautheron et al., "A clonal lineage of Fusarium oxysporum circulates in the tap water of different French hospitals," Applied and Environmental Microbiology, vol. 82, no. 21, pp. 6483-6489, 2016.

[45] A. G. Varon, S. A. Nouér, G. Barreiros, B. M. Trope, T. Akiti, and M. Nucci, "Antimold prophylaxis may reduce the risk of invasive fusariosis in hematologic patients with superficial skin lesions with positive culture for Fusarium," Antimicrobial Agents and Chemotherapy, vol. 60, no. 12, pp. 7290-7294, 2016.

[46] A. D. van Diepeningen, P. Feng, S. Ahmed, M. Sudhadham, S. Bunyaratavej, and G. S. de Hoog, "Spectrum of Fusarium infections in tropical dermatology evidenced by multilocus sequencing typing diagnostics," Mycoses, vol. 58, no. 1, pp. 4857, 2015.

[47] S. Rasti, M. A. Assadi, L. Iranshahi, M. Saffari, H. R. Gilasi, and M. Pourbabaee, "Assessment of microbial contamination and physicochemical condition of public swimming pools in Kashan, Iran," Jundishapur Journal of Microbiology, vol. 5, no. 3, pp. 450-455, 2012.

[48] P. Godoy, F. Nunes, V. Silva, J. Tomimori-Yamashita, L. Zaror, and O. Fischman, "Onychomycosis caused by Fusarium solani and Fusarium oxysporum in São Paulo, Brazil," Mycopathologia, vol. 157, no. 3, pp. 287-290, 2004.

[49] M. Nucci and E. Anaissie, "Fusarium infections in immunocompromised patients," Clinical Microbiology Reviews, vol. 20, no. 4, pp. 695-704, 2007.

[50] C. Krishnaraj, R. Ramachandran, K. Mohan, and P. T. Kalaichelvan, "Optimization for rapid synthesis of silver nanoparticles and its effect on phytopathogenic fungi," Spectrochimica Acta-Part A: Molecular and Biomolecular Spectroscopy, vol. 93, pp. 95-99, 2012.

[51] H. S. Sultana, M. Ali, and B. P. Panda, "Influence of volatile constituents of fruit peels of Citrus reticulata Blanco on clinically isolated pathogenic microorganisms under In-vitro," Asian Pacific Journal of Tropical Biomedicine, vol. 2, no. 3, pp. S1299S1302, 2012.

[52] P. Singh, R. Shukla, B. Prakash et al., "Chemical profile, antifungal, antiaflatoxigenic and antioxidant activity of Citrus maxima Burm. and Citrus sinensis (L.) Osbeck essential oils and their cyclic monoterpene, DL-limonene," Food and Chemical Toxicology, vol. 48, no. 6, pp. 1734-1740, 2010.

[53] M. Chutia, P. Deka Bhuyan, M. G. Pathak, T. C. Sarma, and P. Boruah, "Antifungal activity and chemical composition of Citrus reticulata Blanco essential oil against phytopathogens from North East India," LWT - Food Science and Technology, vol. 42, no. 3, pp. 777-780, 2009.

[54] W. F. Falco, A. M. Queiroz, J. Fernandes et al., "Interaction between chlorophyll and silver nanoparticles: A close analysis of chlorophyll fluorescence quenching," Journal of Photochemistry and Photobiology A: Chemistry, vol. 299, pp. 203-209, 2014.

[55] A. M. Queiroz, A. V. Mezacasa, D. E. Graciano et al., "Quenching of chlorophyll fluorescence induced by silver nanoparticles," Spectrochimica Acta - Part A: Molecular and Biomolecular Spectroscopy, vol. 168, pp. 73-77, 2016. 
[56] M. I. Hussain and M. J. Reigosa, "A chlorophyll fluorescence analysis of photosynthetic efficiency, quantum yield and photon energy dissipation in PSII antennae of Lactuca sativa L. leaves exposed to cinnamic acid," Plant Physiology and Biochemistry, vol. 49, no. 11, pp. 1290-1298, 2011.

[57] A.-J. Miao, K. A. Schwehr, C. Xu et al., "The algal toxicity of silver engineered nanoparticles and detoxification by exopolymeric substances," Environmental Pollution, vol. 157, no. 11, pp. 3034-3041, 2009.

[58] A. Barbasz, B. Kreczmer, and M. Oćwieja, "Effects of exposure of callus cells of two wheat varieties to silver nanoparticles and silver salt (AgNO3)," Acta Physiologiae Plantarum, vol. 38, no. 3, article no. 76, pp. 1-11, 2016. 

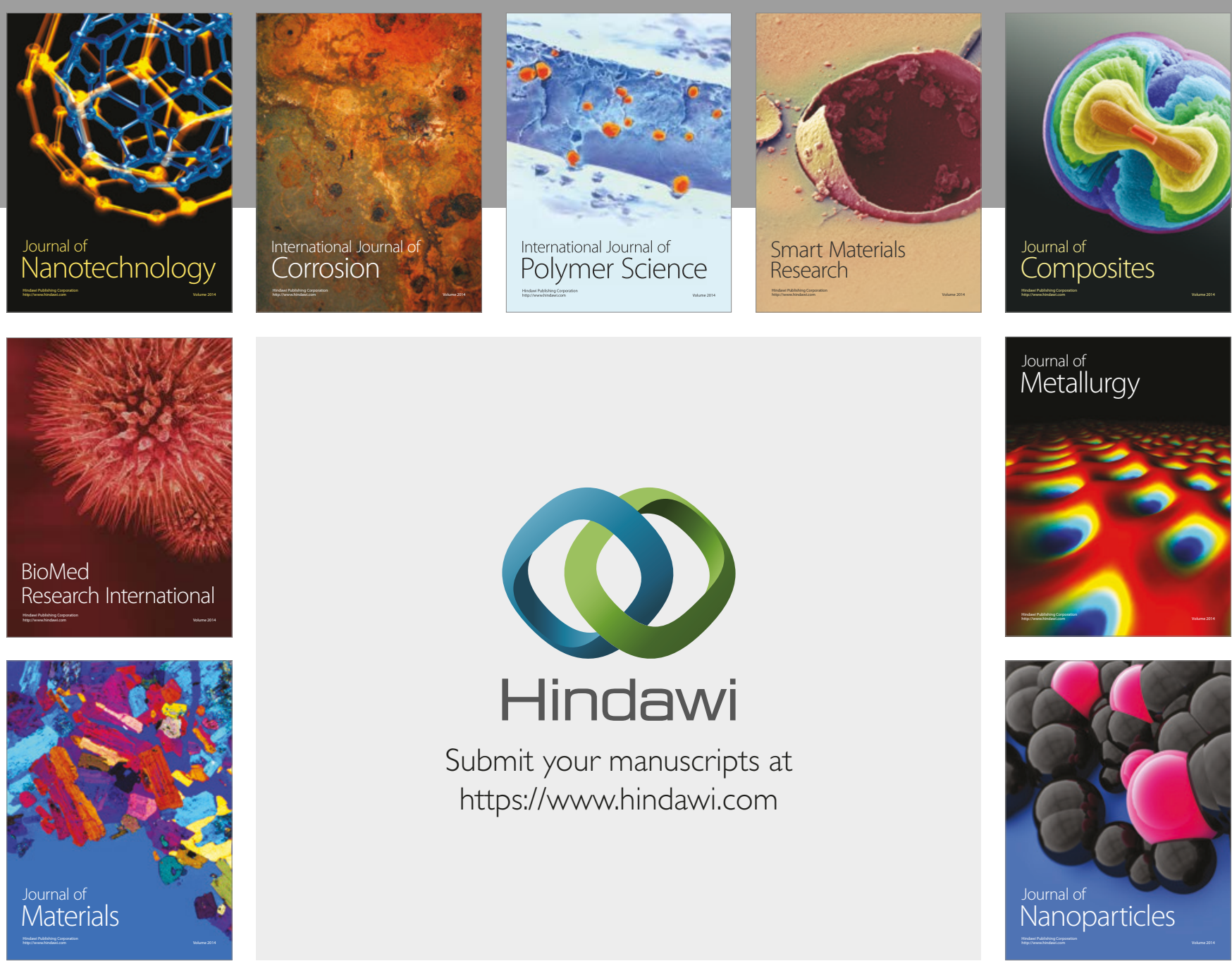

\section{Hindawi}

Submit your manuscripts at

https://www.hindawi.com
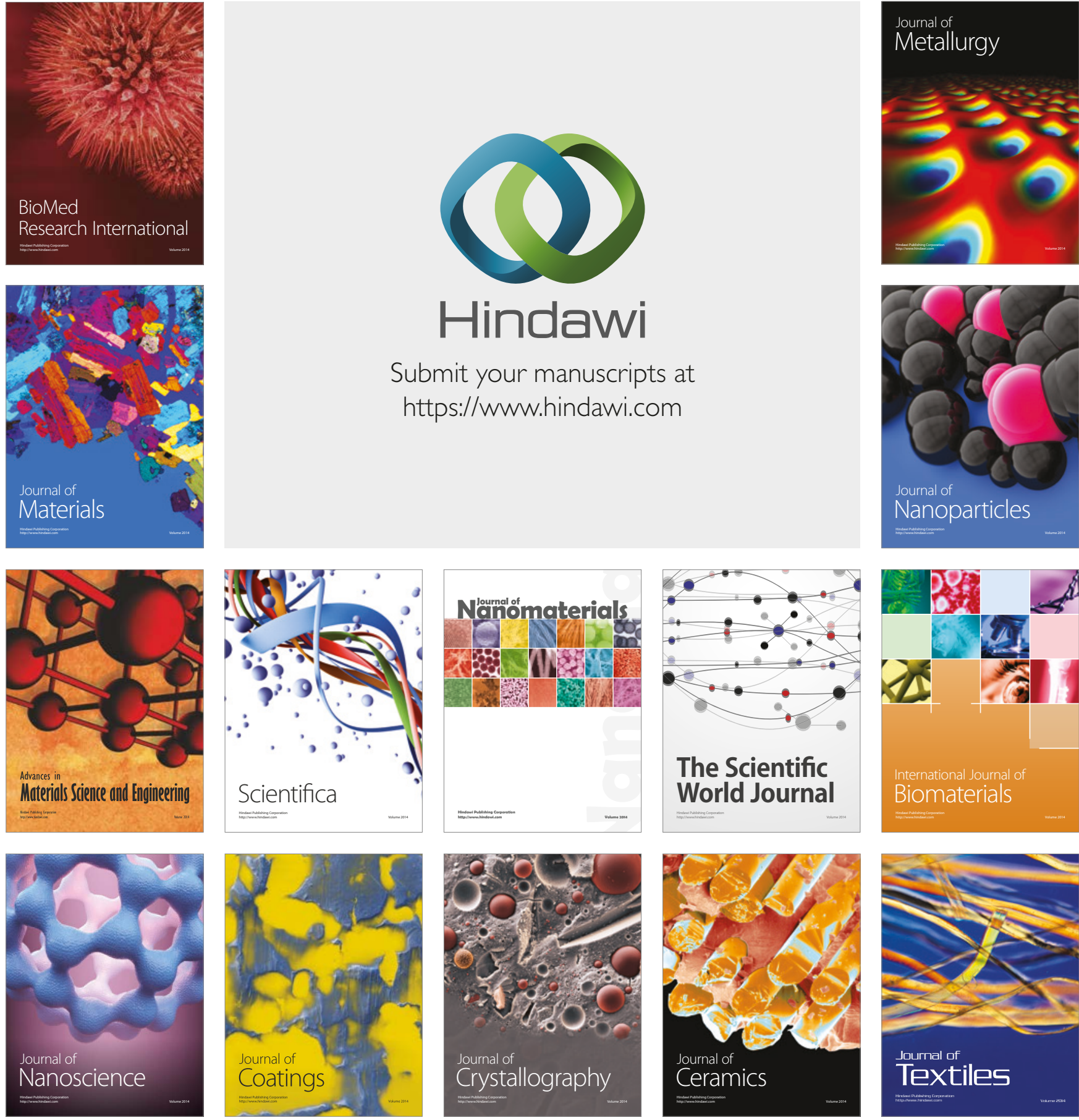

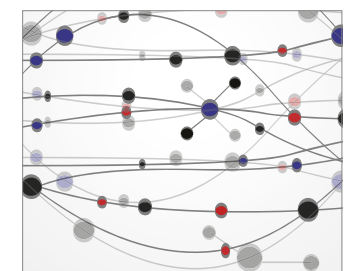

The Scientific World Journal
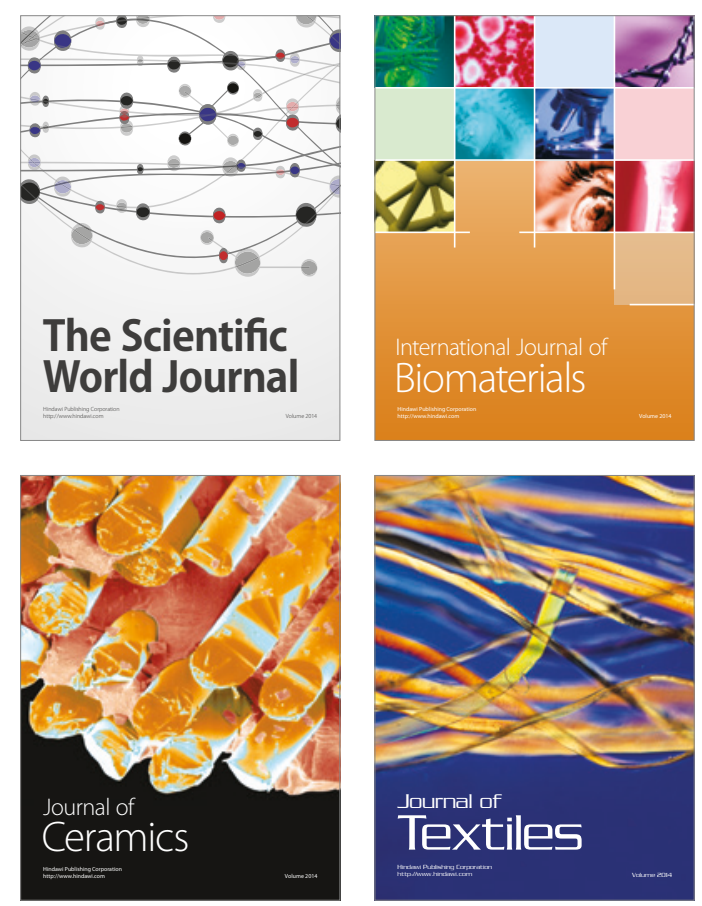